\title{
Agrobacterium rhizogenes mediated genetic transformation resulting in hairy root formation is enhanced by ultrasonication and acetosyringone treatment
}

\author{
Vinod Kumar \\ Plant Cell Biotechnology Department \\ Central Food Technological Research Institute \\ Mysore - 570 020, Karnataka State, India \\ Tel: 9108212516501 \\ Fax: 9108212517233 \\ E-mail: pcbt@cftri.res.in \\ Ashwani Sharma \\ Plant Cell Biotechnology Department \\ Central Food Technological Research Institute \\ Mysore - 570 020, Karnataka State, India \\ Tel: 9108212516501 \\ Fax: 9108212517233 \\ E-mail: pcbt@cftri.res.in

\section{Plant Cell Biotechnology Department Central Food Technological Research Institute \\ Mysore - 570 020, Karnataka State, India \\ Tel: 9108212516501 \\ Fax: 9108212517233 \\ E-mail: pcbt@cftri.res.in \\ Harishchandra Bhaskar Gururaj \\ Plant Cell Biotechnology Department \\ Central Food Technological Research Institute \\ Mysore - 570 020, Karnataka State, India \\ Tel: 9108212516501 \\ Fax: 9108212517233 \\ E-mail: pcbt@cftri.res.in} \\ Bellur Chayapathy Narasimha Prasad
}

\section{Gokare Aswathanarayana Ravishankar* \\ Plant Cell Biotechnology Department Central Food Technological Research Institute Mysore - 570 020, Karnataka State, India \\ Tel: 9108212516501 \\ Fax: 9108212517233 \\ E-mail: pcbt@cftri.res.in}

Financial support: Department of Biotechnology, Government of India for research grants and Council of Scientific and Industrial Research (CSIR) New Delhi for the award of research fellowships to VK, AS, BCNP and HBG.

Keywords: Agrobacterium rhizogenes, hairy roots, Nicotiana tabacum, transformation frequency, ultra-sonication.

Abbreviations: LB: Luria Bertani

MS: Murashige and Skoog

PCR: Polymerase Chain Reaction

The phytopathogenic bacteria Agrobacterium rhizogenes genetically transforms plants by transferring a portion of the resident $R i$ plasmid, the T-DNA to the plant. Plant species differ in their temporal competence for transformation. But various physical and chemical methods are found to enhance transformation frequency. Agrobacterium rhizogenes mediated transformation efficiency was assessed under the influence of sonication, calcium treatment, acetosyringone and macerating enzymes in suitable

*Corresponding author 
combinations in Nicotiana tabacum as a model system. Manual wounding resulted in $21 \%$ transformation frequency. Where as sonication resulted in 2.2 fold increase, followed by sonication with $\mathrm{CaCl}_{2}$ treatment resulted in 2.5 fold increase and sonication with acetosyringone treatment resulted in 4.1 fold increase in transformation frequency. However, sonication with macerating enzyme treatment resulted in 1.5 to 5.25fold decrease in transformation frequency. Micro wounding through sonication followed by acetosyringone treatment enhanced transformation frequency substantially. The results of this study may be very useful in genetic manipulation of plants by Agrobacterium rhizogenes mediated gene delivery to higher plants, which are recalcitrant to A. tumefaciens mediated genetic manipulation.

Various species of bacteria are capable of transferring genes to higher plant species (Broothaerts et al. 2005). Among them, most widely studied ones are Agrobacterium tumefaciens and Agrobacterium rhizogenes. The soil bacterium Agrobacterium rhizogenes infects the plant tissues and leads to the formation of adventitious roots or it is called as "hairy roots". Various plant species differ greatly in their susceptibility to infection by Agrobacterium rhizogenes, Agrobacterium tumefaciens and other bacterial species which are capable of gene transfer to plants (Broothaerts et al. 2005). Many reports suggest the use of Agrobacterium rhizogenes for expression of the rol genes and also to deliver foreign genes to susceptible plants (Christey, 2001). The hairy root harbours the T-DNA segment of Ri-plasmid within its nuclear genomes (Chilton et al. 1982). A. rhizogenes are also capable of transferring the T-DNA of binary vectors in trans, thereby facilitating the selection of transgenic plants from screened hairy roots (Christey, 2001). Agrobacterium rhizogenes mediated transformation system was found to be very useful in genetic manipulation of plants for the production of phytochemicals (Shanks and Morgan, 1999), large scale secondary metabolite production (Choi et al. 2000), monoclonal antibody production (Wongsamuth and Doran, 1997) and phytoremediation (Nedelkoska and Doran, 2000). There are many reports that suggest the successful use of $A$. rhizogenes harbouring binary vectors with desired gene constructs (Christey, 2001) for plant genetic transformation. A number of factors in Agrobacterium mediated transformation process can limit transformation of a particular plant. These include the genotype, wounding of plant tissue, synthesis of phenolic vir gene inducers by the plant, bacterial attachment, T-DNA transfer into the plant cytoplasm, T-DNA nuclear translocation and T-DNA integration (Gelvin, 2000). In order to enhance transformation rates, improvements have been made in various steps involved in genetic transformation. Ultrasonication has been successfully used to deliver and express foreign DNA in protoplasts (Choudhary and Chin, 1995). Moreover ultrasonication was found to be useful in Agrobacterium tumefaciens mediated gene delivery to callus and somatic embryos.
Till date, there are no reports available on influence of physical and chemical treatments on enhancement of transformation rates in $A$. rhizogenes mediated transformation. In this study we carried out extensive work on enhancement of transformation efficiency in Nicotiana tabacum as a model system and conclusively elucidated for the first time that ultrasonication and acetosyringone treatment is highly effective for obtaining transgenics using A. rhizogenes.

\section{MATERIALS AND METHODS}

\section{Plant material and bacterial strain}

Seeds of tobacco (Nicotiana tabacum var. Anand 115) were surface sterilized with $0.1 \%$ mercuric chloride (Hi-media Mumbai, India) cultured on MS basal media (Murashige and Skoog, 1962) without any phytohormone for in-vitro germination. Approximately $2 \times 2 \mathrm{~cm}$ square leaf discs from 20 to 25 day old plant were used for infecting with $A$. rhizogenes. Agrobacterium rhizogenes strain A4 (Kind gift from Dr. Juan B. Perez, Spain) was grown on LB medium and used for all the treatment.

\section{General protocol for co-cultivation and induction of hairy roots}

The leaf explants of Tobacco were co-cultivated with Agrobacterium rhizogenes for infection to induce hairy roots. Agrobacterium cultures were maintained by sub culturing onto a $100 \times 15 \mathrm{~mm}$ culture tubes containing 25 $\mathrm{ml}$ Luria Bertani (LB) slant medium and grown in LB broth for $48 \mathrm{hrs}$ in the dark at $28^{\circ} \mathrm{C}$. The leaf segments were subjected to different physical and chemical treatments prior to A. rhizogenes co-cultivation. The combination of treatments have been summarized in Table 1. For cocultivation, wounded segments with all the treatments were immersed in the bacterial broth culture of $\mathrm{OD}_{600 \mathrm{~nm}}(\sim 18$ $\mathrm{mg} / \mathrm{ml}$ ) and swirled for $15-30 \mathrm{~min}$. The explants were blotted to remove excess of bacterial inoculum. LB liquid medium without bacteria was applied to the explants as a control.

A minimum of 20 explants were used for each experiment. All the explants were cultured on sterilized petriplates comprising semi solid MS (Murashige and Skoog, 1962) medium without phytohormones, however supplemented with sucrose $30 \mathrm{~g} \mathrm{~L}^{-1}$ and myo-inositol $100 \mathrm{mg} \mathrm{L}^{-1}$ (Himedia Mumbai, India) The medium was gelled with $0.8 \%$ (w/v) agar (Hi-media Mumbai, India). The $\mathrm{pH}$ was adjusted to $5.8 \pm 0.2$. The medium was autoclaved under 1.06 $\mathrm{kg} / \mathrm{cm}^{2}$ pressure at $121^{\circ} \mathrm{C}$ for $15 \mathrm{~min}$.

\section{Manual wounding of leaf disc explants}

The leaf discs were kept in disposable sterile petriplate, pricked manually with metal needle $\left(\sim 10\right.$ wounds $\left./ \mathrm{cm}^{2}\right)$ (Table 1, Treatment A), dipped in Agrobacterium rhizogenes culture and incubated in a shaker at $70 \mathrm{rpm}$ for $30 \mathrm{~min}$ in dark. The explants were blot dried using sterile 
Table 1. Summary of treatments subjected to leaf segments of Nicotiana tabacum prior to co-cultivation with $A$. rhizogenes.

\begin{tabular}{|c|c|}
\hline Treatmen & t Sequence of treatments prior to co-cultivation or during co-cultivation \\
\hline A & Manual wounding \\
\hline B & Ultra-sonication \\
\hline C1 & Ultra-sonication + Pectinase ${ }^{a} 0.1 \%$ \\
\hline $\mathrm{C} 2$ & Ultra-sonication + Pectinase ${ }^{a} 0.5 \%$ \\
\hline C3 & Ultra-sonication + Pectinase ${ }^{a} 1 \%$ \\
\hline D1 & Ultra-sonication + Cellulase $^{\mathrm{a}} 0.1 \%$ \\
\hline D2 & Ultra-sonication + Cellulase $^{\mathrm{a}} 0.5 \%$ \\
\hline D3 & Ultra-sonication + Cellulase ${ }^{a} 1 \%$ \\
\hline E1 & Ultra-sonication + Pectinase and Cellulase ${ }^{\mathrm{a}} 0.1 \%$ \\
\hline E2 & Ultra-sonication + Pectinase and Cellulase ${ }^{\mathrm{a}} 0.5 \%$ \\
\hline E3 & Ultra-sonication + Pectinase and Cellulase ${ }^{a} 1 \%$ \\
\hline $\mathrm{F} 1$ & Ultra-sonication + acetosyringone $\mathrm{b}^{\mathrm{b}} 50 \mu \mathrm{M}$ \\
\hline F2 & Ultra-sonication + acetosyringone ${ }^{\mathrm{b}} 100 \mu \mathrm{M}$ \\
\hline F3 & Ultra-sonication + acetosyringone $e^{\mathrm{b}} 150 \mu \mathrm{M}$ \\
\hline G1 & Ultra-sonication $+\mathrm{CaCl}_{2}{ }^{\mathrm{b}} 5 \mathrm{mM}$ \\
\hline G2 & Ultra-sonication $+\mathrm{CaCl}_{2}{ }^{\mathrm{b}} 10 \mathrm{mM}$ \\
\hline G3 & Ultra-sonication $+\mathrm{CaCl}_{2}{ }^{\mathrm{b}} 20 \mathrm{mM}$ \\
\hline
\end{tabular}

${ }^{\text {a }}$ Prior to co-cultivation with $A$. rhizogenes.

${ }^{b}$ During co-cultivation with $A$. rhizogenes.

filter paper and inoculated on co-cultivation medium as described above.

\section{Ultra sonication of leaf segments}

Sonication assisted Agrobacterium tumefaciens mediated transformation (Trick and Finer, 1997) was modified and adopted for transformation experiments. The leaf segments were taken in a $50 \mathrm{ml}$ polypropylene tube (Tarson, India) and ultrasonicated (Bandelin Sonoplus ultrasonicator, Germany) at $50 \mathrm{MHz}$ for $10-100 \mathrm{sec}$ at $80 \%$ amplitude (Table 1, Treatment B). The duration and frequency of sonication was standardized by series of initial experiments. The sonicated explants dipped in Agrobacterium rhizogenes culture incubated in a shaker at $70 \mathrm{rpm}$ for $30 \mathrm{~min}$ in dark. The explants were blot dried using sterile filter paper and inoculated on co-cultivation medium.

\section{Macerozyme treatment of sonicated leaf segments}

The explants were sonicated as described above. Macerating enzymes pectinase (P 9932, Sigma Chemical Co, USA) 0.1 to $1 \%$ v/v (Table 1, Treatment C1, C2, C3) and cellulase (Onozuka R-10 Yakult Pharmaceutical Industry Co., Ltd, Japan) 0.1 to $1 \% \mathrm{w} / \mathrm{v}$ (Table 1, Treatment D1, D2, D3), was freshly prepared and dispensed in cell wall degrading enzyme solution $\left(\mathrm{KH}_{2} \mathrm{PO}_{4}\right.$ $27.2 \mathrm{gml}^{-1}$, KI $0.16 \mathrm{gml}^{-1}, \mathrm{CuSO}_{4} .5 \mathrm{H}_{2} \mathrm{O} 0.025 \mathrm{gml}^{-1}, \mathrm{KNO}_{3}$ 


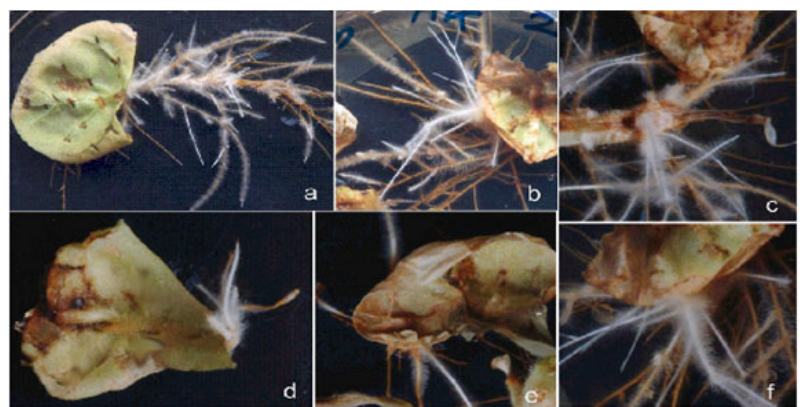

Figure 1. Induction of genetically modified hairy roots under different treatments.

(a) Induction of hairy roots by manual wounding.

(b) Induction of hairy roots by ultrasonication.

(c) Induction of hairy roots by ultrasonication and $100 \mathrm{mM}$ acetosyringone reatments.

(d) Induction of hairy roots by ultrasonication and $0.1 \%$ cellulase treatments.

(e) Induction of hairy roots by ultrasonication and $0.1 \%$ each cellulase and pectinase treatments.

(f) Induction of hairy roots by ultrasonication and $10 \mathrm{mM}$ calcium chloride treatments.

$0.101 \mathrm{gml}^{-1}, \mathrm{MgSO}_{4} \cdot 7 \mathrm{H}_{2} \mathrm{O} 0.246 \mathrm{mgl}^{-1}$, Mannitol 9\% (Himedia Mumbai, India), 2-(N-Morpholino)-ethane-sulphonic acid (Sigma USA)-KOH $\left[\mathrm{P}^{\mathrm{H}} 5.8\right] 3 \mathrm{mM}$ ). The leaf discs were sonicated and treated with either cellulase and pectinase alone or in combination (Table 1, Treatment E1, E2, E3) at concentration of $0.1-1 \%$ each or in combination for partial cell wall degradation for $1 \mathrm{hr}$ in a shaker at 70 rpm under dark. The explants were washed thoroughly to remove traces of cellulase and pectinase enzyme. The explants after sonication and macerating enzyme treatments were dipped in Agrobacterium rhizogenes culture incubated in a shaker at $70 \mathrm{rpm}$ for $30 \mathrm{~min}$ in dark. The explants were blot dried using sterile filter paper and inoculated on cocultivation medium.

\section{Treatment with acetosyringone}

Acetosyringone (Sigma USA) $50 \quad-150 \quad \mu \mathrm{M}$ was incorporated in the co-cultivation medium (Table 1, Treatment F1, F2, F3). This was filter sterilized using 0.22 $\mu \mathrm{m}$ disposable sterile syringe filter (Sartorius, USA) added to sterilized, cooled co-cultivation medium. The sonicated explants dipped in A. rhizogenes culture incubated in a shaker at $70 \mathrm{rpm}$ for $30 \mathrm{~min}$ in dark. The explants were blot dried using sterile filter paper and inoculated on cocultivation medium.

\section{Calcium treatment}

Five to $20 \mathrm{mM} \mathrm{CaCl}_{2}$ (Hi-media Mumbai, India) was incorporated in co-cultivation medium (Table 1, Treatment G1, G2, G3). The sonicated explants dipped in Agrobacterium rhizogenes culture incubated in a shaker at $120 \mathrm{rpm}$ for $30 \mathrm{~min}$ in dark. The explants were blot dried using sterile filter paper and inoculated on co-cultivation medium.

\section{Elimination of $\boldsymbol{A}$. rhizogenes from hairy roots}

The cultures were incubated in the dark for 24 hrs, they were then transferred to fresh MS medium containing cefotaxime $0.5 \mathrm{~g} \mathrm{~L}^{-1}$ (Alkem Laboratories Ltd., Mumbai, India) augmentin $0.3 \mathrm{~g} \mathrm{~L}^{-1}$ (Glaxo Smithkline, Mumbai, India). Hairy roots were made bacteria free by transferring to fresh medium for every 15 days containing the antibiotics mentioned above. The bacteria free hairy roots were maintained in flask cultures containing $40 \mathrm{ml}$ hormone free MS liquid media. The roots were checked for Agrobacterium contamination by culturing hairy root samples on LB medium.

\section{Detection of Ri T-DNA integration}

The Polymerase Chain Reaction (PCR) was used to detect the Ri T-DNA integration in hairy roots. The bacteria-free roots grown in MS basal medium were removed, dried on sterile filter paper and quickly frozen in liquid $\mathrm{N}_{2}$. Thereafter, genomic DNA from putative transformed and normal roots was extracted using Gen Elute DNA extraction kit (Sigma USA)). PCR was performed to detect the rol A gene using a set of rol A specific primer pair (Sigma USA). A $308 \mathrm{bp} \mathrm{rol} \mathrm{A} \mathrm{gene} \mathrm{fragment} \mathrm{was} \mathrm{amplified}$ by using the following primer sets. Forward- 5'AGAATGGAATTAGCCGGACTA-3' and reverse- 5'GTATTAATCCCGTAGGTTTGTTT-3'. The PCR mixture $(25 \mu \mathrm{l})$ contained $50 \mathrm{ng}$ of DNA prepared from normal and hairy roots respectively as the template, $1 \mathrm{X}$ PCR buffer, 25 pmoles of each primer, $2.5 \mathrm{mM}$ of dNTPs and 1 unit of Taq DNA polymerase (MBI Fermentas, Lithuania). PCR for rol A was carried out by amplifying with initial denaturation at $94^{\circ} \mathrm{C}$ for $5 \mathrm{~min}$ followed by 35 cycles of 1 min denaturation at $94^{\circ} \mathrm{C}, 1 \mathrm{~min}$ annealing at $55^{\circ} \mathrm{C}$ and $1 \mathrm{~min}$ extension at $72^{\circ} \mathrm{C}$ with a final extension of $72^{\circ} \mathrm{C}$ for 10 min using a thermal cycler (MWG Biotech, Germany). PCR was performed using vir $\mathrm{C}$ genes to detect the presence of

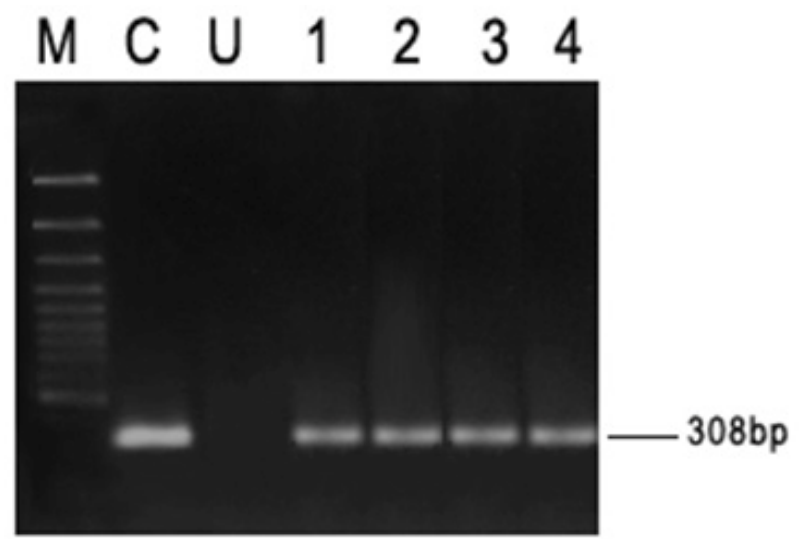

Figure 2. PCR amplification of 308 bp fragment of rol A gene in Nicotiana tabacum hairy root. Lanes M: 100 bp Marker; C:- Template DNA from Agrobacterium rhizogenes plasmid; U: Untransformed roots of Nicotiana tabacum; 1-4: Template DNA from Nicotiana tabacum hairy roots. 
contaminating Agrobacterium in the hairy roots. The PCR conditions were same as those used for amplifying the rol A gene. The primers (Sigma USA) for vir C were, 5, ATCATTTGTAGCGACT-3' and 5'AGCTCAAACCTGCTTC-3'. For the PCR products obtained were run on $1 \%$ agarose gel, stained with ethidium bromide, observed and documented using a transilluminator equipped with a gel documentation system (Herolab GMBH, Germany). The amplified DNA from the agarose gel transferred to nylon membrane (Sambrook et al. 2001) and probed using psoralen biotin (Ambion, USA) labelled $308 \mathrm{bp}$ fragment of the rol A gene obtained from Agrobacterium rhizogenes according to the manufacturer's instructions and hybridisation signals were detected by using Biodetect Kit (Ambion, USA).

\section{Analysis of results}

The results were expressed in percentage transformation frequency.

$$
\% \text { Transformation }=\frac{\begin{array}{c}
\text { Number of explants } \\
\text { inducing hairy roots }
\end{array}}{\begin{array}{c}
\text { Total number of explants } \\
\text { infected with } \text { A. rhizogenes }
\end{array}} \times 100
$$

Fifty to 60 leaf explants were inoculated with $A$. rhizogenes for each treatment in each experiment and 25 explants were cultured as positive and negative control using live and killed A. rhizogenes respectively for infection. All the experiments were carried out in triplicate and the results were expressed as mean \pm SD. Statistical analysis was performed according to Tukey (1953).

\section{RESULTS}

Hairy roots were formed only from wounded regions. Each type of infection and wounding method showed unique pattern of hairy root induction with varying percentage of

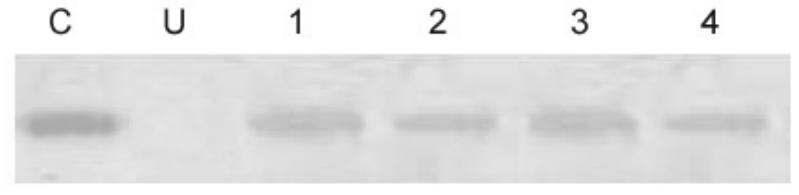

Figure 3. Confirmation of transgenic nature of hairy roots by southern hybridization of the PCR amplicons obtained with rol A gene specific primers. Lanes C: Agrobacterium rhizogenes; U: Untransformed Nicotiana tabacum roots; 1-4: Nicotiana tabacum hairy roots.

transformation frequency (Figure 1). Infection of leaf explants by manual wounding resulted in induction of hairy roots originating from the mid vein region (Figure 1a). However, sonication treatment alone and with acetosyringone and calcium ion treatments resulted in induction of hairy roots from all over the surface of the leaf explants (Figure 1b-f).

Persisting A. rhizogenes contamination was eliminated by frequent subcultures on medium containing antibiotics. Bacteria free root tips were cultured on liquid medium. We observed profuse growth of the hairy roots in liquid MS medium devoid of growth regulators and antibiotics. The transgenic nature of hairy roots was confirmed by PCR using rol A specific primers in bacteria free hairy roots DNA. A 308 bp rol A expected size fragments was obtained only in hairy roots and absent in normal roots (Figure 2). This amplicon reacted with the rol A specific probe in southern hybridization confirmed the transgenic nature of the roots (Figure 3). Culturing the hairy root samples in LB medium did not show the bacterial growth indicating the absence of live A. rhizogenes. PCR with vir $\mathrm{C}$ primers revealed the absence of contaminating $A$. rhizogenes (data not shown).

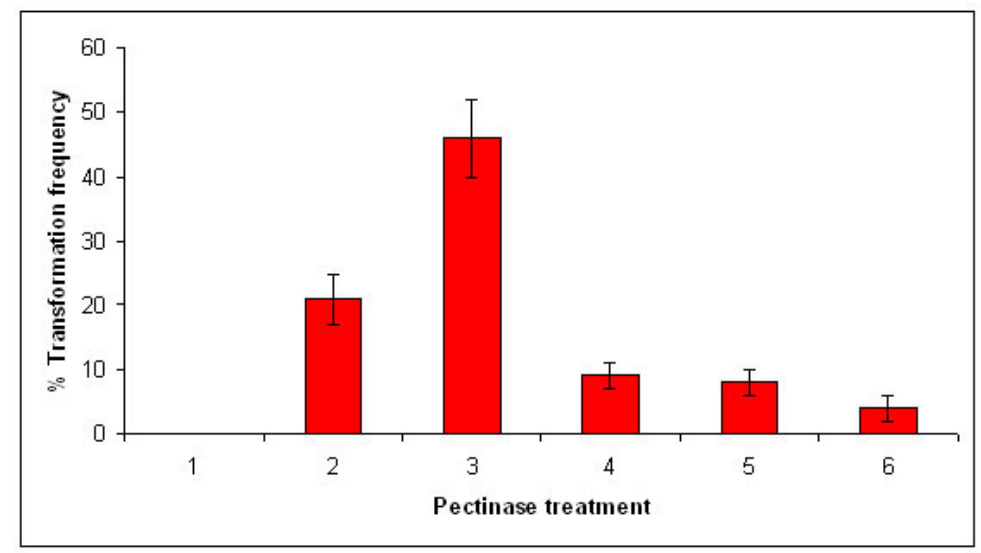

The data is significant at $P>0.01$.

Figure 4. Influence of ultra sonication with pectinase enzyme treatment on transformation frequency. Legends: 1: Control (No Agrobacterium rhizogenes infection); 2: Manual wounding prior to co cultivation (A); 3: Sonication treatment prior to co cultivation (B); 4: Sonication with $0.1 \%$ pectinase enzyme treatment prior to co cultivation $(\mathrm{C} 1)$; 5 : Sonication with $0.5 \%$ pectinase enzyme treatment prior to co cultivation (C2); 6 -Sonication with $1 \%$ pectinase enzyme treatment prior to co cultivation (C3). 


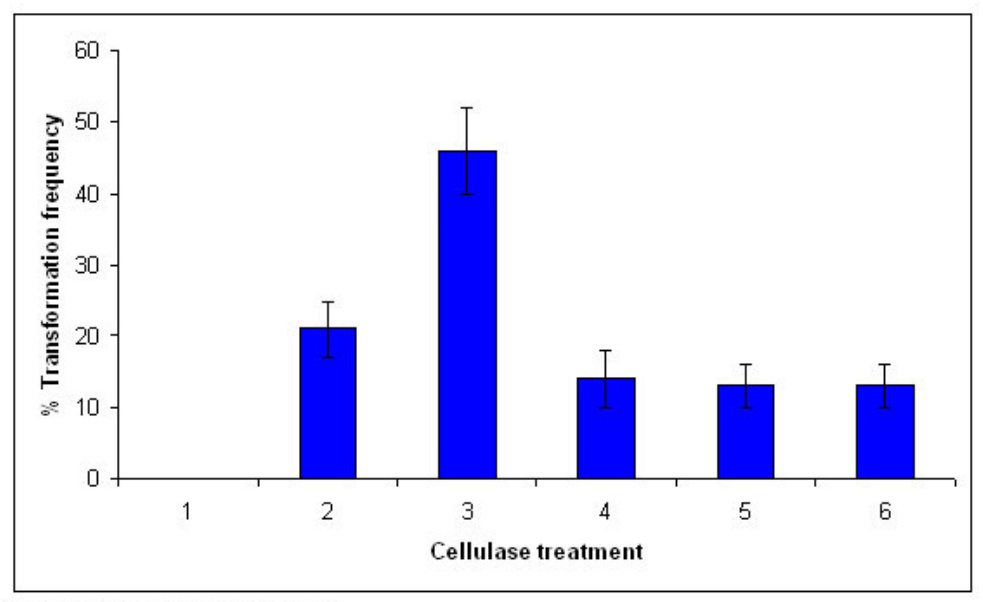

The data is significant at $P>0.01$.

Figure 5. Influence of ultra sonication with cellulase enzyme treatment on transformation frequency. Legends: 1: Control (No Agrobacterium rhizogenes infection); 2: Manual wounding prior to co cultivation (A); 3: Sonication treatment prior to co cultivation (B); 4: Sonication with $0.1 \%$ cellulase enzyme treatment prior to co cultivation (D1); 5 : Sonication with $0.5 \%$ cellulase enzyme treatment prior to co cultivation (D2); 6 : Sonication with $1 \%$ cellulase enzyme treatment prior to co cultivation (D3).

Manual wounding resulted in $21 \%$ transformation frequency. The control explants inoculated with only LB medium devoid of Agrobacterium rhizogenes did not show induction of roots. Macerating enzyme treatment in combination with sonication resulted in reduced transformation frequency (Figure 4, Figure 5, Figure 6). Sonication treatment of leaf explants resulted in 2.2 fold increase in terms of transformation frequency when compared to manual wounding (Figure 4). Sonication assisted transformation resulted in $46 \%$ transformation frequency (Figure 4). There was slight increase in transformation frequency when $20 \mathrm{mM}$ calcium chloride was used in co cultivation medium. Sonication with $5 \mathrm{mM}$ $\mathrm{CaCl}_{2}$ treatment resulted in 2.5 fold increase with a transformation frequency of $52 \%$. Whereas $60 \%$ transformation was obtained at $10 \mathrm{mM} \mathrm{CaCl}_{2}$ (Figure 7). Sonication with $100 \mu \mathrm{M}$ acetosyringone treatment resulted in 4.1 fold increase with $86 \%$ transformation frequency (Figure 8) This treatment was found to be the best for enhancing the transformation frequency. Among all theses treatments, sonication with macerating enzyme treatment resulted in 1.5 to 5.25 -fold decrease in transformation frequency compared to manual wounding treatment (Figure 4, Figure 5 and Figure 6). Less than 6\% explants were showing induction of hairy roots. Use of cellulase or pectinase alone or in combination at higher concentrations such as $0.5 \%$ and $1 \%$ resulted in severe damage to the explants and found to cause lot of problems in rescuing the explants from bacterial over growth. In general sonication in combination with acetosyringone gave excellent results in terms of transformation frequency as well as number of transformation events in each individual explants.

\section{DISCUSSION}

Tobacco serves as an excellent model system to study the factors influencing genetic transformation. Agrobacterium rhizogenes is used to express rol genes and also to deliver foreign genes to susceptible plants. A number of reports available on enhancing the transformation rate in $A$. tumefaciens mediated gene transfer. There is increasing need for studies on enhancement in gene transfer efficiency in other bacteria such as A. rhizogenes, Rhizobium sp NGR234, Sinorhizobium meliloti and Mesorhizobium loti which are capable of gene transfer to higher plants (Broothaerts et al. 2005). However this is the first report on the use of physical and chemical treatments by which the transformation efficiency by $A$. rhizogenes can be enhanced. This would be useful in genetic transformation of other recalcitrant plants.

Wounding is a prerequisite for the genetic transformation process through Agrobacterium and may aid in the production of signal phenolics (Gelvin, 2000) and enhance the accessibility of putative cell-wall binding factors (Gelvin, 2000) to the bacterium. Acetosyringone is one such compound used successfully to enhance transformation in various plant species in A. tumefaciens mediated genetic transformation. Similar observations have been made in our studies.

The cell wall disruption caused by the lower energy ultrasonic frequency utilized in the present study is apparently very useful for Agrobacterium rhizogenes mediated transformation. Although the average expression obtained with various sonication treatments did not differ significantly, the large extent of micro wounding observed with longer treatment indicated that the $30 \mathrm{sec}$ treatment was more suitable for further experiments. Meurer and others (1998) reported the enhancement in transgene delivery to soybean cotyledonary nodes by Agrobacterium tumefaciens mediated transformation. Sonication has been used to enhance Agrobacterium tumefaciens mediated transformation of many different plant species (Trick and Finer, 1997; Santarem et al. 1998). Bidney and others (1992) reported synergistic effect of micro projectile bombardment plant tissues with Agrobacterium 


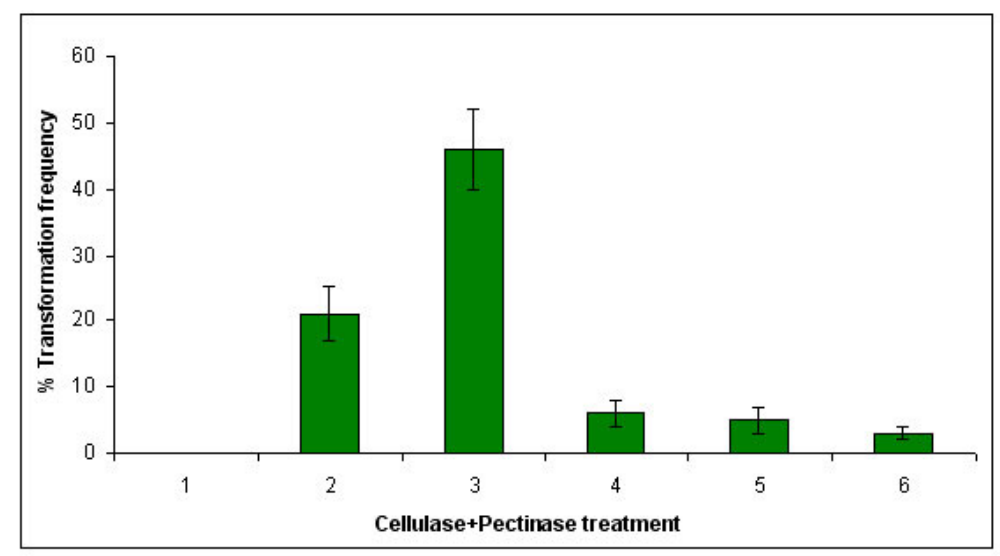

The data is significant at $P>0.01$.

Figure 6. Influence of ultra sonication with cellulase and pectinase enzyme treatment on transformation frequency. Legends: 1: Control (No Agrobacterium rhizogenes infection); 2: Manual wounding prior to co cultivation (A); 3: Sonication treatment prior to co cultivation (B); 4: Sonication with $0.1 \%$ cellulase and pectinase enzyme treatment prior to co cultivation (E1); 5 : Sonication with $0.5 \%$ cellulase and pectinase enzyme treatment prior to co cultivation (E2); 6: Sonication with $1 \%$ cellulase and pectinase enzyme treatment prior to co cultivation (E3).

tumefaciens and found to increase the transformation rate. We have tested the synergistic effect of ultra-sonication with $A$. rhizogenes mediated transformation. This is the first report in which ultrasonication has been tried and found to enhance transformation rates in A. rhizogenes mediated genetic transformation.

Calcium is an essential plant nutrient and required for various signalling pathways (White and Broadley, 2003; Sanders et al. 1999). Since calcium ions are known to increase the permeability of the biological membranes, we wanted to test its effect on gene transfer in higher plants.

Macerating enzymes such as cellulases, pectinases, which are regularly used in protoplast isolation procedures (Alibert et al. 1994), could represent a less disruptive method to remove the cell wall barrier. Following the digestion, the area where Agrobacterium can attach to plant cells might increase for enhanced transformation. In order to test this hypothesis we examined the effect of macerating enzymes on the transformation efficiency in tobacco leaves. In order to assess the effects of macerating enzymes, we compared enzyme treatment and mechanical wounding of the explant by sonication. But the results clearly demonstrated that, the macerating enzyme treatment drastically reduces the transformation efficiency.

Acetosyringone has been known to enhance transformation efficiency due to activation of vir genes in A. tumefaciens (Gelvin, 2000). Therefore we presume that the enhancement in transformation by acetosyringone treatment may be due to activation of vir genes which is absolutely required for the T-DNA delivery to plant tissues. Tang (2003) demonstrated that, incorporation of additional

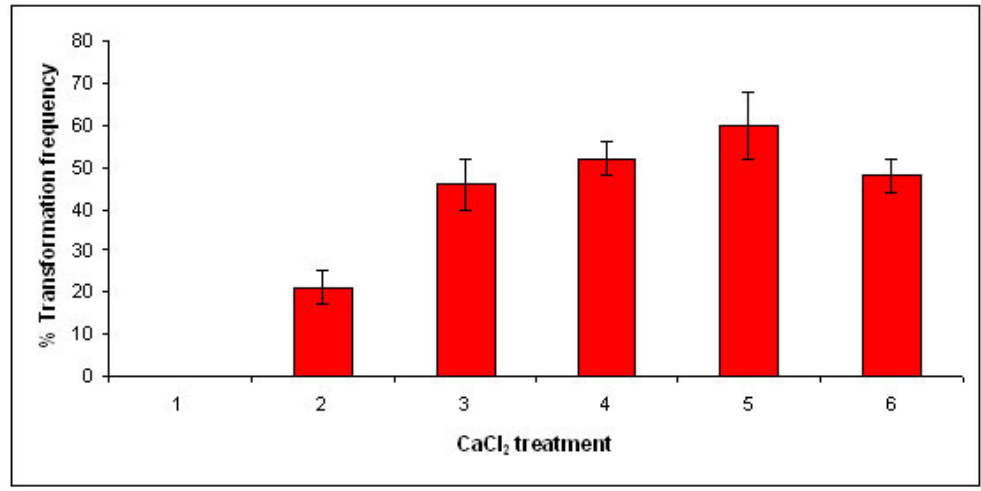

The data is significant at $P>0.01$.

Figure 7. Influence of ultra sonication with calcium ion treatment on transformation frequency. Legends: 1: Control (No Agrobacterium rhizogenes infection); 2: Manual wounding prior to co cultivation (A); 3: Sonication treatment prior to co cultivation (B); 4: Sonication with $5 \mathrm{mM} \mathrm{CaCl}_{2}$ in the co cultivation medium (G1); 5: Sonication with $10 \mathrm{mM} \mathrm{CaCl}_{2}$ in the co cultivation medium (G2); 6: Sonication with $20 \mathrm{mM} \mathrm{CaCl}_{2}$ in the co cultivation medium (G3). 


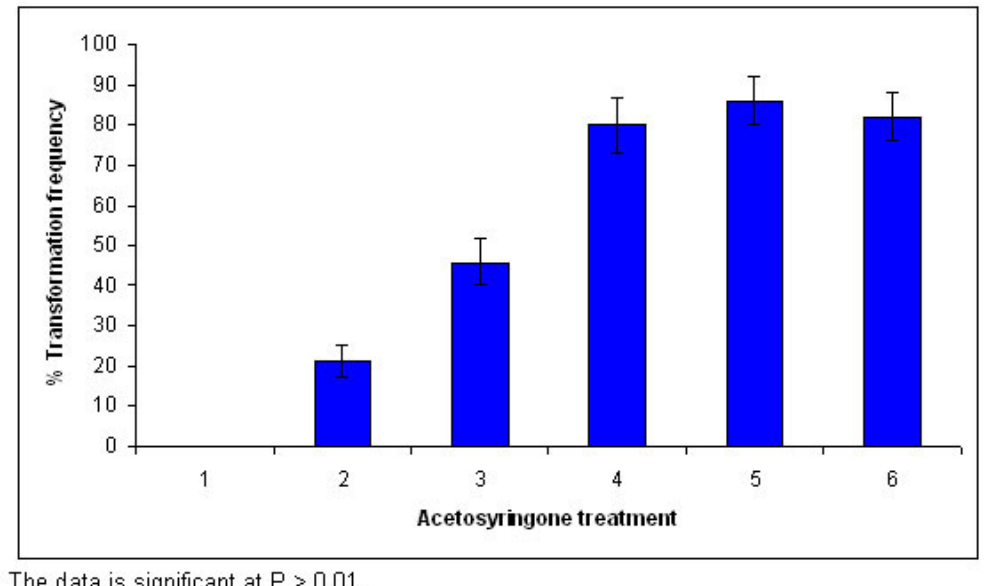

Figure 8. Influence of ultra sonication with acetosyringone treatment on transformation frequency. Legends: 1: Control (No Agrobacterium rhizogenes infection); 2: Manual wounding prior to co cultivation (A); 3: Sonication treatment prior to co cultivation (B); 4: Sonication with $50 \mu \mathrm{M}$ acetosyringone in the co cultivation medium (F1); 5: Sonication with $100 \mu \mathrm{M}$ acetosyringone in the co cultivation medium (F2); 6: Sonication with $150 \mu \mathrm{M}$ acetosyringone in the co cultivation medium (F3).

virulence genes and sonication treatment can enhance Agrobacterium tumefaciens mediated transformation in loblolly pine.

We conclude that, wounding of host tissue by ultrasonication and treatment with acetosyringone followed by exposure to $A$. rhizogenes results in enhanced transformation frequency. This may be useful in transfer of genes to recalcitrant plants using $A$. rhizogenes.

\section{REFERENCES}

ALIBERT, G.; ASLANE-CHANABE, C. and BURRUS, M. Sunflower tissue and cell cultures and their use in biotechnology. Plant Physiology and Biochemistry, 1994, vol. 32, no. 1, p. 31-44.

BIDNEY, Dennis; SCELONGE, Chris; MARTICH, Joanie; BURRUS, Monique; SIMS, Lynn and HUFFMAN, Gary. Microprojectile bombardment of plant tissues increases transformation frequency by Agrobacterium tumefaciens. Plant Molecular Biology, January 1992, vol. 18, no. 2, p. 301-313.

BROOTHAERTS, Wim; MITCHELL, Heidi J.; WEIR, Brian; KAINES, Sarah; SMITH, Leon M.A.; YANG, Wei; MAYER, Jorge E.; ROA-RODRIGUEZ, Carolina and JEFFERSON, Richard A. Gene transfer to plants by diverse species of bacteria. Nature, February 2005, vol. 433, p. 629-633.

CHILTON, Mary-Dell; TEPFER, David A.; PETIT, Annik; DAVID, Chantal; CASSE-DELBART, Francine and TEMPE, Jacques. Agrobacterium rhizogenes inserts TDNA into the genomes of the host plants root cells. Nature, February 1982, vol. 295, p. 432-434.
CHOI, Sung Mee; SON, Sung Ho; YUN, Seung Rho; KWON, Oh Woung; SEON, Jeong Hoon and PAEK, Kee Yoeup. Pilot-scale culture of adventitious roots of ginseng in a bioreactor system. Plant Cell, Tissue and Organ Culture, January 2000, vol. 62, no. 3, p. 187-193.

CHRISTEY, Mary C. Use of Ri-mediated transformation for production of transgenic plants. In Vitro Cellular and Development Biology-Plant, November-December 2001, vol. 37 , no. 6, p. 687-700.

CHOUDHARY, M.L. and CHIN, C.K. Ultrasound mediated delivery of compounds into petunia protoplasts and cells. Journal of Plant Biochemistry and Biotechnology, 1995, vol. 4, p. 37-39.

GELVIN, Stanton B. Agrobacterium and plant genes involved in T-DNA transfer and integration. Annual Review of Plant Physiology and Plant Molecular Biology, June 2000, vol. 51, p. 223-256.

MEURER, C.A.; DINKINS, R.D. and COLLINS, G.B. Factors affecting soybean cotyledonary node transformation. Plant Cell Reports, December 1998, vol. 18, no. 3-4, p. 180-186.

MURASHIGE, Toshio and SKOOG, Folke. A revised medium for rapid growth and bioassays with tobacco tissue cultures. Physiologia Plantarum, July 1962, vol. 15, no. 3, p. 473-497.

NEDELKOSKA, Tatjana V. and DORAN, Pauline M. Hyperaccumulation of cadmium by hairy roots of Thlapsi caerulescens. Biotechnology and Bioengineering, March 2000, vol. 67, no. 5, p. 607-615. 
SAMBROOK, J.; FRITSCH, E.F. and MANIATIS, T. Molecular Cloning. A Laboratory Manual, Cold Spring Harbor Laboratory Press, Cold Spring Harbor, 2001, New York. ISBN 0879695773. 999 p.

SANDERS, Dale; BROWNLEE, Colin and HARPER, Jeffrey F. Communicating with calcium. The Plant Cell, April 1999, vol. 11, no. 4, p. 691-706.

SANTAREM, E.R.; TRICK, H.N.; ESSIG, J.S. and FINER, J.J. Sonication-assisted Agrobacterium-mediated transformation of soybean immature cotyledons: optimization of transient expression. Plant Cell Reports, July 1998, vol. 17, no. 10, p. 752-759.

SHANKS, Jacqueline V. and MORGAN, John. Plant 'hairy root' culture. Current Opinion in Biotechnology, April 1999, vol. 10, no. 2, p. 151-155.

TANG, W. Additional virulence genes and sonication enhance Agrobacterium tumefaciens- mediated loblolly pine Transformation. Plant Cell Reports, February 2003, vol. 21, no. 6, p. 555-562.

TRICK, Harold N. and FINER, John J. SAAT: Sonicationassisted Agrobacterium-mediated transformation. Transgenic Research, September 1997, vol. 6, no. 5, p. 329-336.

TUKEY, J.W. Some selected quick and easy methods of statistical analysis. Transactions of the New York Academy of Sciences, December 1953, vol. 16, no. 2, p. 88-97.

WONGSAMUTH, R. and DORAN, P.M. Hairy root as an experimental system for production of antibodies. In: DORAN, P.M. ed. Hairy roots, Culture and applications. Amsterdam, Harwood, 1997, p. 89-97.

WHITE, Philip J. and BROADLEY, Martin R. Calcium in plants. Annals of Botany, October 2003, vol. 92, no. 4, p. 487-511. 